\title{
BACTERIOSTATIC AND LYTIC ACTIONS OF PENICILLIN ON SENSITIVE AND RESISTANT STAPHYLOCOCCI ${ }^{1}$
}

\author{
By WILLIAM M. M. KIRBY
}

(From the Department of Medicine, Stanford University School of Medicine, San Francisco)

(Received for publication July 17, 1944)

In contrast to other bacteria, staphylococci undergo lysis when allowed to multiply in the presence of bacteriostatic concentrations of penicillin. As noted previously (1), all penicillin sensitive strains are lysed, whereas insensitive strains resist this lytic action. The following observations clarify certain fundamental aspects of both lysis and bacteriostasis, and have important clinical as well as theoretical implications.

\section{EXPERIMENTAL}

The general methods have been described in detail elsewhere (1). For the present study, large inocula (10 to 50 million organisms per $\mathrm{ml}$.) of $\mathbf{1 0 0}$ penicillin-sensitive strains of Staph. aureus (coagulase positive), isolated from patients with furuncles, abscesses, or osteomyelitis, were

1 The penicillin was provided by the Office of Scientific Research and Development from supplies assigned by the Committee on Medical Research for experimental investigations recommended by the Committee on Chemotherapeutics and Other Agents of the National Research Council. added to tubes containing synthetic medium plus the following concentrations of penicillin, $0.1,1.0,10$, and $100 \mathrm{U}$. per ml., and growth was measured turbidimetrically at various intervals for from 3 to 7 days. With 10 of the strains, plate counts were made from each tube daily for 3 days, and further tests of viability of the organisms were carried out after 7 days.

In addition, 8 strains of penicillin-resistant staphylococci obtained from clinical sources were tested by the serial dilution technic (2), as well as by the above method, in an attempt to correlate resistance with lysis and bacteriostasis.

\section{RESULTS}

A typical lysis experiment is shown graphically in Figure 1. With $0.1 \mathrm{U}$. per $\mathrm{ml}$. of penicillin there was greater initial growth than with the higher concentrations. This was followed by rapid lysis, so that, after 24 hours, the tube containing $0.1 \mathrm{U}$. per $\mathrm{ml}$. was much less turbid than those with $1.0,10$, and $100 \mathrm{U}$. per ml. of penicillin. This phenomenon, which occurred with each of the 100 strains, was so.striking that

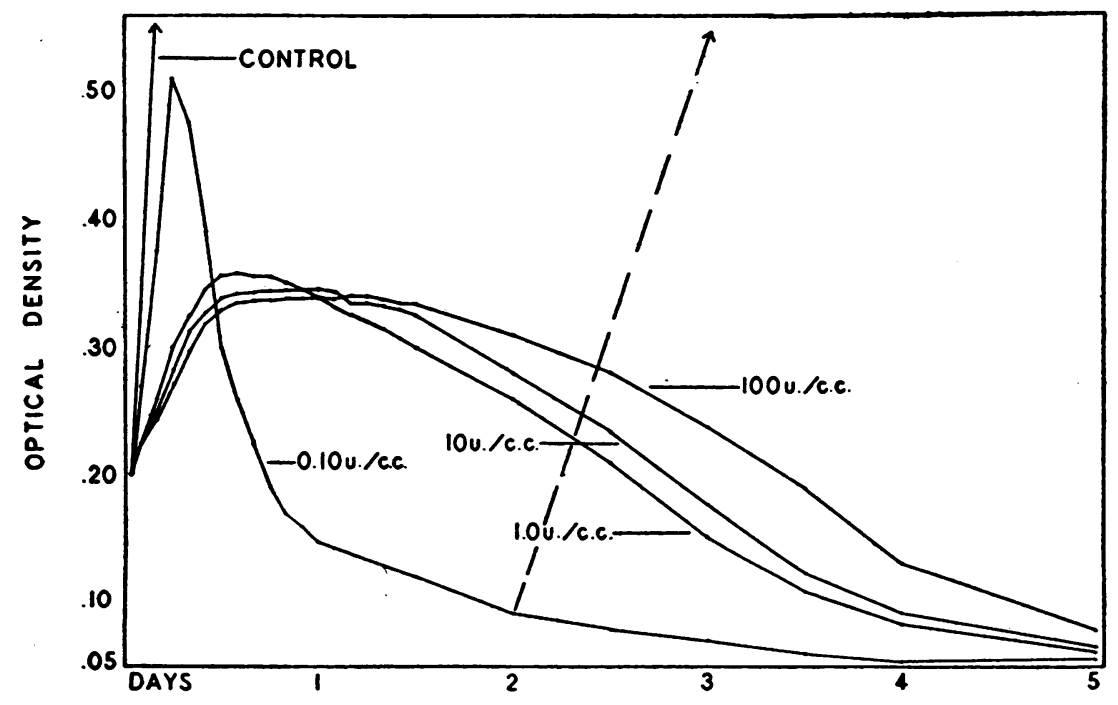

Fig. 1. Growth and Lysis of a Strain of Staphylococcus aureus Measured TURBIDIMETRICALLY

The correlation between penicillin concentration and degree and rate of lysis is clearly demonstrated. 
TABLE I

Results of plate counts in a typical lysis experiment

Fewer viable organisms were present with $0.1 \mathrm{U}$. per ml. than with $100 \mathrm{U}$. per ml. of penicillin. $\mathrm{X}=$ too many colonies to count accurately.

\begin{tabular}{l|c|c|c|r}
\hline \hline & $10^{-3}$ & $10^{-4}$ & $10^{-6}$ & $10^{-6}$ \\
\hline 24 hours & & & & \\
Control & $\mathrm{X}$ & $\mathrm{X}$ & $\mathrm{X}$ & 810 \\
0.1 U. per ml. & $\mathrm{X}$ & $\mathrm{X}$ & 200 & 28 \\
100 U. per ml. & $\mathrm{X}$ & $\mathrm{X}$ & 684 & 79 \\
& & & & \\
48 hours & $\mathrm{X}$ & $\mathrm{X}$ & $\mathrm{X}$ & 540 \\
Control & $\mathrm{X}$ & 42 & 3 & 0 \\
0.1 U. per ml. \\
100 U. per ml. & $\mathrm{X}$ & 600 & 43 & 2 \\
72 hours & & & & \\
Control & $\mathrm{X}$ & $\mathrm{X}$ & $\mathrm{X}$ & 500 \\
0.1 U. per ml. & 21 & 16 & .1 & 0 \\
100 U. per ml. & 594 & 40 & 20 & 0 \\
\hline
\end{tabular}

it could be readily observed grossly by holding the tubes up to the light. After 24 hours, there was gradual lysis in all the tubes containing penicillin, the rate now faster with the higher concentrations, so that after 5 days, turbidities in all the tubes were about the same.

Lysis was closely correlated with destruction of bacteria. Many more viable organisms were present after 24 hours with $100 \mathrm{U}$. per ml. than with $0.1 \mathrm{U}$. per $\mathrm{ml}$, and during the next 72 hours, there was a decrease with both concentrations, the count falling rapidly with $100 \mathrm{U}$. per ml. as lysis occurred. Results of plate counts with a representative strain are presented in Table I. Even after a week, viable organisms could always be recovered from each tube, but this prolonged incubation was in no instance associated with a demonstrable development of penicillin resistance.

With a very heavy inoculum (optical density 0.4), similar results were obtained (Figure 2). Lysis occurred more slowly, but its relation to the concentration of penicillin was the same as with the smaller inoculum.

With 3 strains obtained from blood cultures, there was a secondary growth in the tube containing $0.1 \mathrm{U}$. per ml. (represented by a broken line in Figure 1). This occurred after 48 hours' incubation; i.e., after a large percentage of the organisms had undergone rapid lysis. The staphylococci now present were highly resistant, growing luxuriantly without lysis in the presence of $100 \mathrm{U}$. per ml. of penicillin.

These resistant organisms, plus 5 naturally occurring resistant strains, all responded to the above lysis test in the same manner; a typical example is shown in Figure 3. No lysis oc-

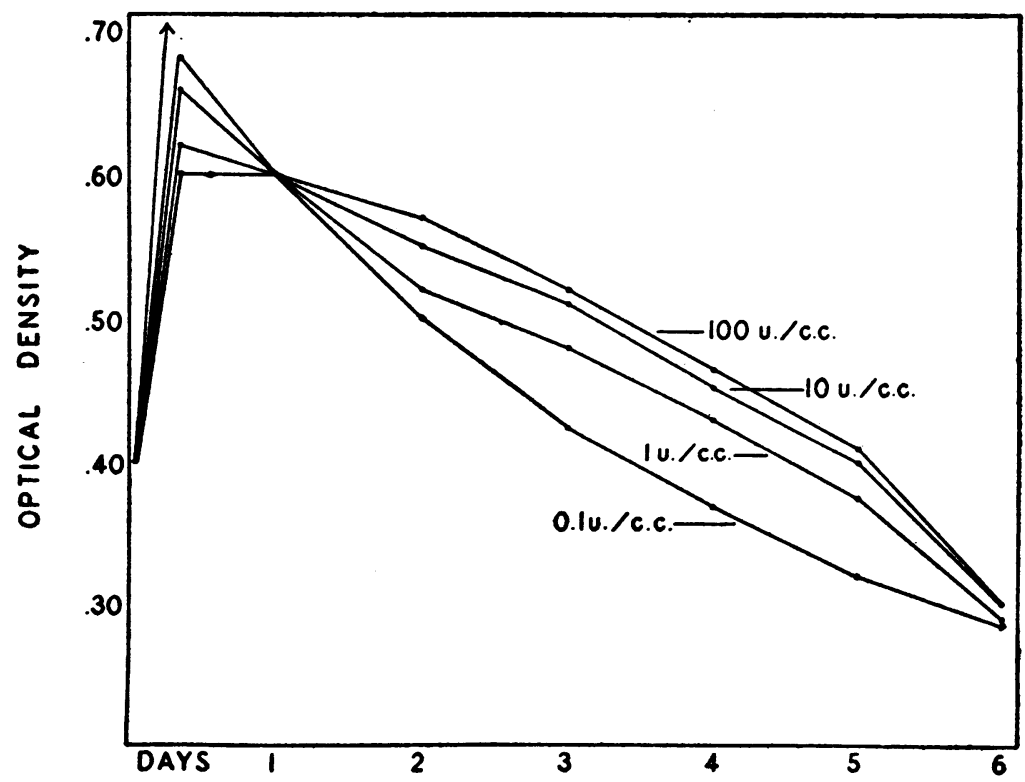

Fig. 2. The Same as Fig. 1, Using a Much Larger Inoculum

Lysis occurred more slowly, but the relation to penicillin concentration was the same as with the smaller inoculum. 


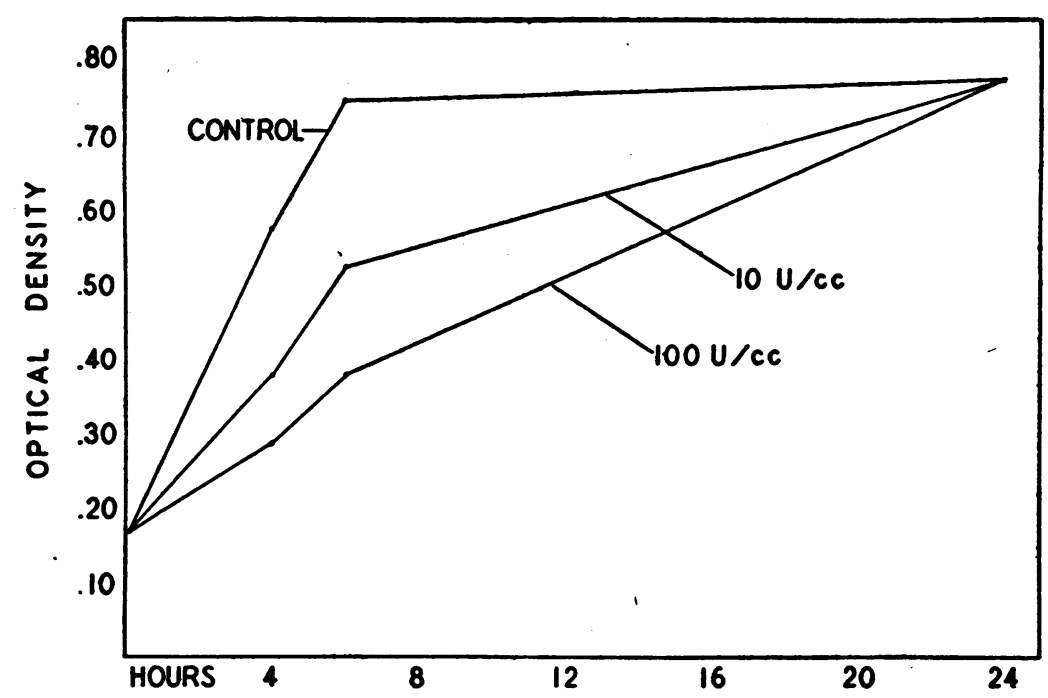

Fig. 3. Growth of a Penicillin-Resistant Staphylococcus in the Presence of Penicillin

Lysis did not occur, but a marked bacteriostatic action was exerted by the penicillin.

curred, but there was a marked bacteriostatic action exerted by the penicillin. As the organisms multiplied and destroyed the penicillin, they gradually overcame the bacteriostatic action, so that, after 24 hours, growth was equal to that of the control. The results with all 8 strains are presented in Table II, and contrasted with two sensitive strains in which there was lysis by $0.1 \mathrm{U}$. per $\mathrm{ml}$.

The results of the Rammelkamp dilution test are also presented in Table .II. With all but 2 of the 8 resistant strains, there was a failure to recover viable organisms in penicillin concentrations of $5 \mathrm{U}$, per ml., or less, after 24 hours.

\section{COMMENT}

A striking correlation between the concentration of penicillin and the degree and rate of lysis was demonstrated in these experiments. Within limits, lysis was more complete and oc-

TABLE II

Results of turbidimetric (inoculum 10 million organisms per ml.) and dilution (inoculum 1000 organisms per ml.) tests with 2 sensitive and 8 resistant strains of $\mathrm{S}$. aureus

\begin{tabular}{|c|c|c|c|c|c|c|c|c|c|c|c|c|}
\hline \multirow[b]{2}{*}{ Strain } & \multicolumn{2}{|c|}{ Turbidimetric test } & \multicolumn{10}{|c|}{ Dilution test } \\
\hline & Initial & $\begin{array}{l}24 \text { hrs. with } \\
0.1 \text { U. } \\
\text { per mi. }\end{array}$ & 5.71 & 2.85 & 1.54 & 0.71 & 0.35 & 0.17 & 0.08 & 0.04 & 0.02 & 0.01 \\
\hline $\begin{array}{l}1 \\
2\end{array}$ & $\begin{array}{l}0.15 \\
0.15\end{array}$ & $\begin{array}{l}0.05 \\
0.04\end{array}$ & $\begin{array}{l}0 \\
0\end{array}$ & $\begin{array}{l}0 \\
0\end{array}$ & $\begin{array}{l}0 \\
0\end{array}$ & $\begin{array}{l}0 \\
0\end{array}$ & $\begin{array}{l}\text { unit } \\
0 \\
0\end{array}$ & $\begin{array}{r}m l . \\
0 \\
0\end{array}$ & $\begin{array}{l}0 \\
0\end{array}$ & $\begin{array}{l}0 \\
+\end{array}$ & + & + \\
\hline $\begin{array}{l}\text { Resist- } \\
\text { ant }\end{array}$ & \multicolumn{2}{|c|}{$\begin{array}{l}\text { Readings for both } 0.1 \\
\text { and } 100 \mathrm{U} \text {. per ml. }\end{array}$} & & & & & & & & & & \\
\hline $\begin{array}{l}1 \\
2 \\
3 \\
4 \\
5 \\
6 \\
7 \\
8\end{array}$ & $\begin{array}{l}0.16 \\
0.15 \\
0.15 \\
0.15 \\
0.14 \\
0.13 \\
0.15 \\
0.15\end{array}$ & $\begin{array}{l}0.83 \\
0.88 \\
0.90 \\
0.89 \\
0.87 \\
0.89 \\
0.93 \\
0.78\end{array}$ & $\begin{array}{l}0 \\
0 \\
0 \\
+ \\
0 \\
0 \\
0 \\
+\end{array}$ & $\begin{array}{l}0 \\
0 \\
0 \\
+ \\
0 \\
+ \\
0 \\
+\end{array}$ & $\begin{array}{l}+ \\
0 \\
+ \\
+ \\
+ \\
+ \\
0 \\
+\end{array}$ & $\begin{array}{l}+ \\
0 \\
+ \\
+ \\
+ \\
+ \\
0 \\
+\end{array}$ & $\begin{array}{l}+ \\
+ \\
+ \\
+ \\
+ \\
+ \\
+ \\
+\end{array}$ & $\begin{array}{l}+ \\
+ \\
+ \\
+ \\
+ \\
+ \\
+ \\
+\end{array}$ & $\begin{array}{l}+ \\
+ \\
+ \\
+ \\
+ \\
+ \\
+ \\
+\end{array}$ & $\begin{array}{l}+ \\
+ \\
+ \\
+ \\
+ \\
+ \\
+ \\
+\end{array}$ & $\begin{array}{l}+ \\
+ \\
+ \\
+ \\
+ \\
+ \\
+ \\
+\end{array}$ & $\begin{array}{l}+ \\
+ \\
+ \\
+ \\
+ \\
+ \\
+\end{array}$ \\
\hline
\end{tabular}


curred more rapidly with smaller than with larger concentrations, presumably because of the greater initial growth of the organisms with smaller concentrations. In other words, the greater the initial growth of the organisms in the presence of a bacteriostatic concentration of penicillin, the more rapid their destruction. It is of interest that the concentration of penicillin causing the most rapid lysis, $0.1 \mathrm{U}$. per ml., is in the range obtained clinically in the blood stream, especially with the continuous intravenous method of administration. A further point of clinical interest is the effect of the lysed cellular elements upon the patient. The prolonged high fever and toxicity in cases of staphylococcus sepsis as opposed to those caused by pneumococci or hemolytic streptococci may be in part due to substances liberated by the lysis of large numbers of staphylococci.

The outgrowth of highly resistant staphylococci in $0.1 \mathrm{U}$. per $\mathrm{ml}$. of penicillin suggests the presence in the culture of a few resistant bacteria which could not multiply rapidly until the majority of the sensitive organisms had been lysed. This suggestion is supported by the observation of the Oxford group that artificially induced resistance of staphylococci is associated with a diminished velocity of growth (3). Virulence of the resistant organisms has not been investigated. The clinical implications of this observation are not clear, but it is worth noting that, in one instance, the secondary outgrowth of resistant staphylococci occurred in the culture from a patient with osteomyelitis whose response to penicillin was unsatisfactory.

These resistant staphylococci have been found to produce an intracellular penicillin inactivator (4) in contrast to sensitive strains which produced no such penicillin-destroying substance. The properties of this penicillin inhibitor have been described (5) and it has been added to routine culture media to inactivate penicillin present in specimens obtained from patients under treatment (6).

In the present experiments with resistant staphylococci, resistance to lysis and resistance to bacteriostasis have been clearly differentiated. In Figure 3, for example, penicillin exerted a marked bacteriostatic action on the organisms, although lysis did not occur. At the end of 24 hours, growth in the presence of penicillin was equal to that of the controls; a single observation made at this time would have conveyed the impression that this strain of S. aureus was "completely resistant" to the bacteriostatic action of penicillin, when such was actually not the case. The dilution tests, summarized in Table III, demonstrated a further important point in regard to the size of the inoculum. With a small inoculum (1000 to 30,000 organisms per $\mathrm{ml}$.), viable organisms could not be recovered in most instances after 24 hours with penicillin concentrations of $5 \mathrm{U}$. per $\mathrm{ml}$. or less, whereas there was luxuriant growth in the presence of $100 \mathrm{U}$. per $\mathrm{ml}$. with the large inoculum (10 million organisms per ml.) used for the turbidimetric test. This was apparently due to the inability of the smaller number of bacteria to multiply a sufficient number of times to destroy even relatively small concentrations of penicillin. It is evident then that resistance is a relative matter. Resistant organisms produce a penicillin destroying substance, but are themselves susceptible to the bacteriostatic action of penicillin, and will not survive unless they are present in sufficient numbers to inactivate the penicillin with which they are in contact. This concept should be borne in mind in performing and interpreting tests designed to determine the sensitivity of staphylococci to penicillin.

The importance of the size of the inoculum is also demonstrated by the experiments with sensitive staphylococci. With the large inoculum used for the turbidimetric tests, viable organisms were recovered after 7 days' incubation in the presence of $100 \mathrm{U}$. per ml., while the small number of bacteria employed for the dilution test were killed within 24 hours by less than $0.1 \mathrm{U}$. per ml. Thus the statement that the action of penicillin is "only influenced to a minor extent by the number of bacteria to be inhibited" (3) must be accepted with definite reservations.

\section{SUMMARY}

1. In vitro studies of the action of penicillin on 100 sensitive and 8 resistant strains of $S$. aureus are reported.

2. A striking correlation was found between the concentration of penicillin and the degree and rate of lysis of sensitive organisms. 
3. In 3 instances, there was a secondary outgrowth of highly resistant staphylococci following the initial rapid lysis of sensitive organisms.

4. Penicillin-resistant organisms were susceptible to the bacteriostatic action of penicillin, but overcame this action by destroying the penicillin when present in sufficient numbers. When present in insufficient numbers, they succumbed to the action of penicillin in the same manner as sensitive staphylococci.

5. The size of the inoculum was found to have an important bearing on the results of sensitivity tests, both with sensitive and resistant staphylococci.

I am indebted to Mrs. Mary Wolohan for technical assistance.

\section{BIBLIOGRAPHY}

1. Rantz, L. A., and Kirby, W. M. M., The action of penicillin on the staphylococcus in vitro. J. Immunol., 1944, 48, 335.

2. Rammelkamp, C. H., and Maxon, T., Resistance of Staphylococcus aureus to the action of penicillin. Proc. Soc. Exper. Biol. and Med., 1942, 51, 386.

3. Abraham, E. P., Chain, E., Fletcher, C. M., Florey, H. W., Gardner, A. D., Heatley, N. G., and Jennings M. A., Further observations on penicillin. Lancet, 1941, 2, 177.

4. Kirby, W. M. M., Extraction of a highly potent penicillin inactivator from penicillin resistant staphylococci. Science, 1944, 99, 452.

5. . Kirby, W. M. M., Properties of a penicillin inactivator extracted from penicillin-resistant staphylococci J. Clin. Invest., 1945, 24, 170.

6. Kirby, W. M. M., Addition of a penicillin inactivator to routine culture media. Stanford M. Bull., 1944, $2,158$. 